\title{
MIDAS
}

Museus e estudos interdisciplinares

\section{Reflexão sobre políticas públicas e gestão de acervos em instituições de memória em Portugal}

A reflection around public policies and collections management in Portuguese memory institutions

Graça Filipe, Conceição Serôdio, Leonor Calvão Borges e Ana Margarida Dias da Silva

\section{OpenEdition}

\section{Journals}

Edição electrónica

URL: https://journals.openedition.org/midas/2704

DOI: $10.4000 /$ midas. 2704

ISSN: $2182-9543$

Editora:

Alice Semedo, Paulo Simões Rodrigues, Pedro Casaleiro, Raquel Henriques da Silva, Ana Carvalho

Refêrencia eletrónica

Graça Filipe, Conceição Serôdio, Leonor Calvão Borges e Ana Margarida Dias da Silva, «Reflexão sobre políticas públicas e gestão de acervos em instituições de memória em Portugal», MIDAS [Online], 13। 2021, posto online no dia 15 dezembro 2021, consultado no dia 06 março 2022. URL: http:// journals.openedition.org/midas/2704 ; DOI: https://doi.org/10.4000/midas.2704

Este documento foi criado de forma automática no dia 6 março 2022.

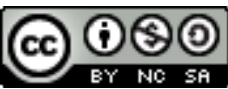

Midas is licensed under a Creative Commons Attribution-NonCommercial-ShareAlike 3.0 International License 


\title{
Reflexão sobre políticas públicas e gestão de acervos em instituições de memória em Portugal
}

\author{
A reflection around public policies and collections management in Portuguese \\ memory institutions \\ Graça Filipe, Conceição Serôdio, Leonor Calvão Borges e Ana Margarida \\ Dias da Silva
}

\section{NOTA DO EDITOR}

Artigo recebido a 30.01.2021

Aprovado para publicação a 26.07.2021

\section{Introdução}

O património cultural, com as suas dimensões tangíveis e intangíveis, representa uma valiosa herança do passado e, ao mesmo tempo, constitui um enorme potencial de recursos para a sociedade contemporânea. Pessoas, comunidades, organizações e instituições que trabalham no setor cultural reconhecem a importância de políticas públicas e de programas nacionais e internacionais, assim como a necessidade de instrumentos de convergência para a valorização, a preservação e o acesso ao património cultural, e de inspiração para a renovação das suas atuações, em diferentes escalas, como por exemplo a Convenção-Quadro do Conselho da Europa Relativa ao Valor do Património Cultural para a Sociedade, também conhecida como Convenção de Faro (Conselho da Europa 2005), os Objetivos de Desenvolvimento Sustentável (ODS) e a Agenda 2030 das Nações Unidas (2015). 
2 As instituições de memória ${ }^{1}$, onde se incluem museus, bibliotecas e arquivos públicos ou privados, de diferentes âmbitos regionais ou nacionais, enquanto serviços ou organizações, surgem associadas à salvaguarda e gestão de património, à ação cultural, social, educacional e à proteção da memória dos países, das comunidades e das instituições, com a inerente produção cultural e de informação.

Com base na legislação - geral, dedicada ao património cultural e setorial, para museus, bibliotecas e arquivos - e tendo por referência bibliografia científica e académica e estudos sobre a matéria, as autoras procuram refletir sobre e problematizar: a questão da gestão das coleções e arquivos em cada uma das instituições de memória; as diferenças e similaridades existentes entre cada uma elas; e o posicionamento de cada uma face à comunicação em ambiente digital e período pós pandémico.

\section{Instituições de memória: inter-relações e complementaridades na valorização de património}

4 Se a revolução francesa e a ideia de nacionalização e acesso público definiram a separação de bens culturais diferentes por diferentes instituições custodiadoras, com base no seu suporte, que conservam a memória universal e transmitem conhecimento e cultura, a desmaterialização e o ambiente digital, onde «bits e bytes são todos iguais» (Timms 2009, 68, tradução das autoras), tendem a quebrar as distinções tradicionais existentes entre documentos de arquivo, livros de bibliotecas e objetos de museus.

5 Na verdade, o ambiente digital e as tecnologias da comunicação e da informação (TIC) voltaram a aproximar arquivos, bibliotecas e museus - instituições com funções análogas de recolha, seleção, aquisição, conservação e salvaguarda física e/ou intelectual, difusão, comunicação, mediação e acesso da informação - daquilo que se pretende que constitua a memória e que seja apropriado como património da humanidade.

6 As coleções e os acervos das três instituições de memória, em princípio estabelecidos de acordo com a tipologia dos documentos e com as missões das entidades custodiais, são fundamentais para garantir a disponibilização de informação (independentemente de suportes, formatos e canais). A gestão das coleções afigura-se, assim, como essencial.

7 Mas até que ponto o suporte de informação do bem cultural (ou objeto) condiciona a seleção, a aquisição e a incorporação (Luna 2011, 25) de determinados bens culturais por cada um dos tipos de instituição de memória? Nesta matéria as instituições de memória posicionam-se de forma diferente e diferenciada.

8 A comunidade arquivística tem sido parca na reflexão sobre o tema, com pouca ou nenhuma publicação (Greene 2015a, 142), em contracorrente com a reflexão que, desde os anos 80 do século XX, a biblioteconomia desenvolve, com prioridades bem definidas de acordo com os objetivos de cada unidade de informação, os seus clientes, extensão e condição dos materiais já existentes e formatos preferidos (Kaczmarek 2007, 216).

Atualmente, com o desenvolvimento da ciência da informação, a passagem de um paradigma custodial (físico, historicista, patrimonialista e tecnicista) para pós-custodial (contextual, informacional, dinâmico, sistémico e científico) (Silva e Ribeiro 2002), é comumente aceite, contrapondo à gestão de documentos a gestão da informação. 
10 Passa-se, assim, da compreensão dos serviços de informação como fechados, com a finalidade de preservação física dos documentos, privilegiando o documento, para serviços abertos ao público, com a finalidade de transmissão de informação e conhecimento, com o enfoque no conteúdo. Termos como "gestão de conteúdos" ou "curadoria da informação", aplicada à gestão da informação nado-digital, vêm especificar essa alteração de posicionamento, sendo as bibliotecas e os arquivos obrigados a refletir e definir políticas de gestão integrada de coleções independentemente do seu suporte.

11 Fernanda Ribeiro $(2005,8)$ refere mesmo que, face ao desenvolvimento tecnológico e aumento exponencial das autoestradas da informação, a "conservação da memória passou a ser um imperativo imediato», advogando a necessidade de uma gestão da informação com qualidade, tornando a seleção da mesma fundamental.

12 E qualquer política de gestão e desenvolvimento de coleção implica, naturalmente, o seu desbaste ou desincorporação. Na comunidade arquivística norte-americana, o termo desincorporação implica a reavaliação da documentação já avaliada (Jackson 2015, 155-157), num processo que Mark Greene (2002) considera fundamental. Para além da reavaliação, impõe-se ainda refletir sobre a quantidade de documentação que é incorporada em arquivo histórico sem ter sofrido um processo de avaliação, situação comum em Portugal.

$13 \mathrm{Na}$ área da biblioteconomia, a reflexão que nos anos 80 do século XX se desenvolve tem já prioridades bem definidas de acordo com os objetivos de cada unidade de informação, os seus clientes, extensão e condição dos materiais já existentes e formatos preferidos (Kaczmarek 2007, 216).

14 De igual forma, a museologia tem desenvolvido reflexão sustentada e termos de referência sobre as políticas de gestão de coleções (Lord e Lord [1997] 2009; Ladkin, 2004; Matassa 2011; Mensch e Meijer-van Mensch 2011; Lord, Lord e Martin 2012; ICOM 2017; ICOM 2019).

15 Ainda que na museologia contemporânea se assuma a coleção como um meio e não como um fim (Mensch e Meijer-van Mensch 2011, 15) e nesse pressuposto os museus não tenham por objetivo primeiro constituir coleções, os objetos (tridimensionais, bidimensionais ou imateriais) detêm um lugar central na maioria destas instituições. $O$ paradigma alterou-se ao longo do tempo e os museus até assumiram integrar os processos de reconhecimento, valorização e salvaguarda de património tendo por foco a sua dimensão imaterial. Os objetos que integram o acervo de um museu, e frequentemente as manifestações culturais imateriais que lhes são associadas, assumem-se património «material e imaterial da humanidade e do seu meio-ambiente» (ICOM 2017, 3, tradução das autoras). ${ }^{2}$ Mas um museu não se equipara simplesmente a um colecionador, nem mesmo a um colecionador de interesse público (Gob e Drouguet $2006,157)$ e a sua aquisição de objetos está sujeita a parâmetros de preservação, de coerência relativamente às atividades de investigação, de interpretação e de exposição, de relevância dos objetos no contexto patrimonial, de acordo com a missão e o âmbito de atuação da entidade museal.

16 Em todos os casos, há dois aspetos a destacar: quer a indissociabilidade entre as políticas de incorporação/desincorporação e os procedimentos subsequentes à aquisição, conduzindo à valorização de património; quer a imprescindibilidade dos processos de inventariação e de acesso público. 
17 Podendo adotar-se termos um pouco diferenciados, a estratégia de desenvolvimento de coleções e a política de gestão de coleção constituem instrumentos vitais de planeamento e programação museológica dos museus (Lord, Lord e Martin 2012, 196, 209-210, 656-657), e devem ser revisitados com frequência (Matassa 2010, 120), principalmente em tempos de mudança.

Uma política de desenvolvimento de coleções em contexto museal é inerente à sua natureza dinâmica e implica considerar, a par da incorporação, a desincorporação (Mensch e Meijer-van Mensch 2011, 19). Este termo, de utilização museológica relativamente recente, dá expressão a profundas transformações ocorridas nos museus, a partir da segunda metade do século XX, para descrever o processo inverso à incorporação (Luna 2011, 39), com importantes discussões ocorridas a partir da década de 1980, nomeadamente na Holanda e no Reino Unido, levando a museologia contemporânea a dar enfoque à política de desenvolvimento de coleções (Mensch e Mensch 2010, 54-55).

19 Embora sob algumas variantes terminológicas, nomeadamente consoante a língua e o país, um crescente número de museólogos tem defendido de forma realista a importância dos critérios de seleção e a indissociabilidade entre os processos de aquisição, de incorporação, de desincorporação e de descarte de objetos, na gestão das coleções museais, implicando ou não a sua alienação, com a devida atenção aos contextos de proveniência, em particular aos doadores e suas famílias ou descendentes (Matassa 2010, 122).

20 A necessidade ou a decisão fundamentada de subtrair um objeto de uma coleção leva a um processo técnico e individualizado, de investigação, análise, avaliação, autorização, confirmação e registo de desincorporação desse mesmo objeto, que, a manter-se propriedade do museu, pode até continuar a requerer cuidados de armazenamento e preservação, para uso no contexto museal (Luna 2011, 40).

21 Um dos pontos de consenso entre especialistas é que, sempre que haja lugar ao descarte ou à alienação de um objeto com obtenção de recursos financeiros, estes sejam exclusivamente aplicados na qualificação das próprias coleções do museu. Não receando defender o procedimento de desincorporação e até mesmo a possibilidade de alienação, importa, portanto, afirmar a necessidade de escolhas fundamentadas e o princípio da coleção responsável (Mairesse 2010, 67).

22 Portugal está referenciado como um dos países que na Europa se têm manifestado menos dispostos a aceitar a desincorporação como um instrumento de gestão das coleções em contextos museais, enquanto outros já desenvolveram as suas normas de apoio a este tipo de procedimento (Wijsmuller 2017). ${ }^{3}$ Cremos necessário evoluir na criação de uma política comum em relação a tal procedimento.

\section{0 quadro legal e institucional português}

23 A Constituição da República Portuguesa identifica a proteção e a valorização do património cultural como uma tarefa fundamental do Estado (art. 9º), cabendo-lhe assegurar o seu acesso, «tornando-o elemento vivificador da identidade cultural comum» (art. 78º $\left., 2^{\circ}, \mathrm{c}\right)$.

24 Acompanhando os processos de mudança e remodelação da Administração Pública portuguesa após a revolução democrática de 1974 até aos dias de hoje, têm sido vários 
os modelos de organização dos serviços do Estado nas áreas do património cultural e dos arquivos, bibliotecas e museus, ora reunindo, ora separando por diferentes entidades as responsabilidades de ação sobre as várias áreas do património.

Atualmente, arquivos e bibliotecas encontram-se sob a tutela da Direção-Geral do Livro, Arquivos e Bibliotecas (DGLAB) e os museus sob a Direção-Geral do Património Cultural (DGPC), embora todos sob a alçada do Ministério da Cultura.

A Lei de Bases do Património Cultural estipula os deveres especiais da Administração de desenvolvimento de legislação que regule a constituição, organização e funcionamento das redes nacionais de arquivos, bibliotecas e museus (art. $22^{\circ}$, $\S 1^{\circ}$ ) e de promoção da cooperação entre os seus serviços e instituições, a qual poderá incluir a cedência e troca de bens culturais sempre que se trate de integrar ou completar coleções ou fundos de natureza histórica ou de especial interesse literário, artístico, científico ou técnico (art. $22^{\circ}, \S 4^{\circ}$ ).

o diploma «estabelece as bases da política e do regime de protecção e valorização do património cultural, como realidade da maior relevância para a compreensão, permanência e construção da identidade nacional e para a democratização da cultura» (art. $\left.1^{\circ}, \S 1^{\circ}\right)$, onde se incluem, como bens culturais móveis, espécies artísticas, etnográficas, científicas e técnicas, bem como espécies arqueológicas, arquivísticas, audiovisuais, bibliográficas, fotográficas, fonográficas e ainda quaisquer outras que

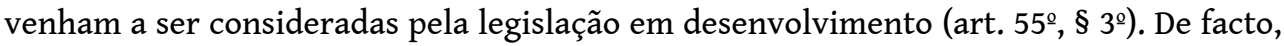
a gestão de acervos e coleções de memória não se baseia em princípios transversais aos três principais tipos de instituições que os reúnem e protegem, principalmente sob tutelas públicas.

O Decreto-Lei n.. 16/93, de 23 de janeiro que estabelece o regime geral dos arquivos e do património arquivístico, identifica a gestão nacional dos arquivos como a «definição dos princípios e regras a que devem obedecer a recolha, o tratamento, a classificação, a conservação e a valorização do património arquivístico» (art. 7.ํ), introduzindo o conceito de gestão de documentos - fundamental também para a constituição de acervos em arquivos históricos - como:

[...] [o] conjunto de operações e procedimentos técnicos que visam a racionalização e a eficácia na criação, organização, utilização, conservação, avaliação, seleção e eliminação de documentos, nas fases de arquivo corrente e intermédio, e na remessa para arquivo definitivo. (art. 13.)

Assim, nos arquivos históricos, a gestão do acervo faz-se atualmente, de duas formas: a incorporação obrigatória de documentação que (idealmente) já passou por um processo de avaliação, seleção e eliminação, ou a aquisição através de compra direta ou em leilão, onde os arquivos nacionais têm direito de preferência, doação ou depósito.

O estabelecimento de critérios de avaliação a utilizar em arquivos públicos iniciou-se com a aprovação do Decreto-Lei n.. 447/88, de 10 de dezembro que regulou a préarquivagem de documentação e a publicação, no âmbito do Instituto Português de Arquivos, das Orientações Gerais sobre Gestão de Documentos de Arquivo, de João Vieira (1990).

31 À publicação de inúmeras portarias de avaliação e seleção de documentos, sucedeu-se, por parte da DGLAB:

[...] [a implementação de um] esquema de metainformação (MIP) e de um modelo suprainstitucional e transversal de classificação e avaliação da informação pública estabelecido a priori para representar as funções, subfunções e os processos de 
negócio executados pela Administração Central, Local e Sector Público Empresarial - a Lista Consolidada, que resulta da aglutinação de três projetos: MEF, Harmonização de classes de $3^{\circ}$ nível em planos de classificação conforme à MEF e Avaliação Suprainstitucional da Informação Arquivística -, em consonância, aliás, com a prática internacional. (Silva, Borges e Freitas 2019, 5)

Apesar destas iniciativas, o diagnóstico aos arquivos intermédios da administração central, feito em 2003, identificou cerca de $700 \mathrm{~km}$ de documentação dispersa, sem avaliação em vários depósitos do Estado. Esta situação tem sido resolvida, em pequena percentagem, através da avaliação das chamadas "massas acumuladas", cuja realização a entidade DGLAB promoveu e orientou.

O regime de incorporações encontra-se regulado no Decreto-Lei n.․ 47/2004, de 3 de março, que define o regime geral das incorporações da documentação de valor permanente em arquivos públicos, existindo orientações para as aquisições em arquivos públicos. De uma forma geral, podemos identificar como tendências de aquisições nos arquivos distritais e municipais, os arquivos de famílias, pessoas e organismos públicos ou privados relevantes para a comunidade que o arquivo serve $\mathrm{e}$ determinantes para a constituição da memória social.

Se o regime geral de incorporações nos arquivos públicos e os requisitos a observar nas incorporações estão estipulados em lei, qualquer regulamentação sobre a desincorporação em arquivos é omissa.

Com uma forte tradição de bibliotecas de caráter patrimonial, acompanhando, aliás, uma tendência de outros países da Europa do sul (Nunes 2018), bibliotecas locais criadas com recurso a doações, e a tradicional suborçamentação do setor, só a partir da segunda metade do século XX surgem em Portugal preocupações com uma política de gestão de coleções de bibliotecas, ainda assim através do Serviço de Bibliotecas de uma fundação privada - a Fundação Calouste Gulbenkian (Melo 2004; Santos 2011).

As bibliotecas públicas só abordaram a questão após a criação, em 1987, da Rede Nacional de Leitura Pública (Decreto-lei n. ${ }^{\circ} 111 / 87$, de 11 de março), na dependência do Instituto Português do Livro e da Leitura (Decreto-lei n. ${ }^{\circ} 71 / 87$, de 11 de fevereiro).

O desenvolvimento das bibliotecas universitárias, a criação da rede de bibliotecas escolares, em 1995, e o crescimento exponencial de coleções mistas (impressas e digitais) fizeram desenvolver, já no século XXI, políticas integradas de gestão de coleções, revelando ainda a necessidade de fazer curadoria da documentação/ informação nado-digital, onde os custos de manutenção de servidores podem ser mais elevados que aqueles dedicados à coleção impressa.

A adoção das diretivas da International Federation of Libraries Association (IFLA) para a gestão de coleções sustentou a criação de políticas de gestão das coleções, com critérios definidos explicitamente para a aquisição e desbaste das mesmas, tanto de âmbito quantitativo, como qualitativo no âmbito da arquivística.

O que se conclui dos pontos acima é que arquivos e bibliotecas têm um posicionamento distinto na forma de gerir as suas coleções e documentos, em relação à forma como os museus o fazem.

A Lei-Quadro dos Museus Portugueses (2004) define os princípios da política nacional e também o princípio de serviço público, ao expressar os museus como instituições abertas à sociedade. Esta Lei-Quadro determina que, para ser credenciada (e integrar a Rede Portuguesa de Museus) cada uma destas instituições terá uma política de 
incorporações definida, (revista e atualizada pelo menos de cinco em cinco anos) de acordo com a sua missão e a sua vocação e consubstanciada num programa museológico que imprima coerência e continuidade (ou enriquecimento) ao respetivo acervo de bens culturais.

A Lei-Quadro dos Museus Portugueses define incorporação, enquanto função museológica, como «a integração formal de um bem cultural no acervo do museu» (art. ${ }^{\circ}$ $13^{\circ}$, n. ${ }^{\circ} 1$ ), implicando todos os procedimentos inerentes à sua gestão em contexto museal.

Não obstante a referida Lei-Quadro equiparar o termo incorporação ao termo aquisição, consideramos que a integração de um objeto nas coleções de um museu envolve dois procedimentos distintos e, normalmente, sequenciais: a aquisição e a incorporação.

Foi também a Lei-Quadro dos Museus Portugueses a determinar que os bens dos museus públicos passassem a integrar o domínio público cultural:

Os bens culturais incorporados em museus que sejam pessoas coletivas públicas ou delas dependentes integram o domínio público do Estado, das regiões autónomas ou dos municípios, conforme os casos. (art. 64)

mesma Lei prevê, porém, a possibilidade de desafetação de bens culturais do domínio público, mediante «autorização do Ministro da Cultura, ouvido o Conselho de Museus» (art. 65ำ § 1).

Assim, a cessação da dominialidade pode ocorrer por decisão expressa da administração ou procedimento de desafetação tácita, por desaparecimento, destruição ou perda da utilidade pública do objeto. Estes casos dão lugar ao seu "abate ao inventário" ou "desincorporação", procedimento que pode ser considerado inverso ao de incorporação (Luna 2011, 39).

O trabalho de Isabel Luna intitulado Incorporação e Desincorporação em Museus: História, Realidade e Perspetivas Futuras é uma das raras abordagens museológicas sobre a desincorporação de bens museológicos, em Portugal: «algo que se pratica, mas que não se vê. (...) assumida como uma ação reservada, do foro próprio de cada museu e insuscetível de discussão ou apreciação pública» (Luna 2011, 91). ${ }^{4}$

Segundo a mesma autora, não obstante a sua asserção legal, a inalienabilidade das coleções públicas portuguesas não pode ser entendida como absoluta, ainda que seja incomum no que diz respeito aos bens culturais móveis e que a lei portuguesa só a admita sob grandes restrições (Luna 2011, 85).

De acordo com o Inquérito aos Museus, em 2018 estavam em atividade 680 museus, dos quais foram considerados para fins estatísticos 431 museus $^{5}$, que registaram 19,5 milhões de visitantes (INE 2019, 90). Do total dos museus apurados, 68\% dependem de entidade de administração central, regional ou local (INE 2019, 118).

Os 431 museus portugueses considerados para fins estatísticos detinham um acervo de 19,8 milhões de bens (INE 2019, 12), representando um aumento de 716,4 mil bens relativamente a 2017 (INE 2019, 93). Por tipologia dos bens, quase 77\% do acervo dos museus era constituído pelo conjunto dos "bens bibliográficos e arquivísticos" (34,4\%), "bens arqueológicos" (19,4\%), "bens naturais não vivos" (12,4\%), "bens artísticos e históricos" (10,5\%), enquanto $18,2 \%$ eram "outros bens", nos quais estão incluídos os bens de filatelia e de fotografia (INE 2019, 109). ${ }^{6}$

50 Importa constatar, no que diz respeito aos museus portugueses, a diversidade e a heterogeneidade, quer de acervos, quer de cadeias operatórias e de gestão a que são 
sujeitos os bens em cada entidade museal. A presente situação realça a necessidade de um sistema integrado de informação, embora se reconheça, entre os próprios profissionais, a dificuldade de passar deste paradigma a práticas implementadas. A salvaguarda de património constituído como acervo de um museu ou de outra instituição de memória só pode ser feita conhecendo o que existe e como é gerido, daí a importância dos inquéritos de diagnóstico para estabelecer políticas de preservação, gestão e investigação.

51 Nesta linha de reflexão e na procura de conhecer quais as principais características dos museus portugueses no que diz respeito às áreas da gestão da informação sobre os seus vários tipos de bens patrimoniais, o Grupo de Trabalho Sistemas de Informação em Museus (GT-SIM) da Associação Portuguesa de Bibliotecários, Arquivistas e Documentalistas (APBAD) ${ }^{7}$ promoveu a realização, em 2016, do estudo Diagnóstico aos Sistemas de Informação nos Museus Portugueses. ${ }^{8}$ Tendo em conta a sua caraterização com base nas variáveis "tutela", "tipo", "região" e "ano de abertura", salienta-se que em termos de dependência institucional, os museus são maioritariamente de tutela pública (75\%), com maior incidência nos dependentes dos municípios (55\%), enquanto os privados representam $23 \%$ na amostra. Pela tipologia, os principais tipos de museus são "arte" e "mistos e pluridisciplinares", que representam cerca de $41 \%$ dos que responderam. Se se juntar os tipos "etnografia e de antropologia" e "especializados", então passam a representar mais de $70 \%$ dos casos. Quanto ao ano de abertura, parte substancial dos museus abriu ao público a partir do ano 2000 (43\%). Se ainda se considerar os com abertura na década de1990, então a percentagem acumulada passa a significar $60 \%$ da amostra. É no período 2000-2009 que se concentra a maior percentagem (27\%) (Santos, Serôdio e Ferreira 2017, 26-27).

52 Em relação aos acervos refere-se que cerca de dois terços dos museus da amostra em análise possuíam pelo menos dois tipos de acervo, sendo os mais comuns o museológico e o bibliográfico. Museus com bens de todos os tipos de acervo são $32 \%$. Por outro lado, são $35 \%$ os museus que mencionaram apenas possuir acervo museológico (Santos, Serôdio e Ferreira 2017, 79-80). Tendo em conta a informatização do inventário desses acervos, salienta-se que $83 \%$ dos museus assinalou ter o inventário em suporte informático. Um terço dos museus possuía pelo menos dois dos seus acervos naquele suporte, destacando-se de novo o acervo museológico e bibliográfico. Outro terço dos museus apenas tem informatizado o seu acervo museológico. Com os três acervos nesta condição encontram-se 17\% dos museus (Santos, Serôdio e Ferreira 2017, 83).

No que diz respeito aos documentos orientadores utilizados para a gestão das coleções e informação dos bens nos museus, o estudo permitiu ainda apurar que a situação difere consoante o tipo de acervo: no museológico, 37\% refere ter um documento com a política de incorporação de coleções; no bibliográfico, são $22 \%$ os que têm um com a política de aquisição/desenvolvimento de coleções; e no arquivístico, são $16 \%$ com plano de gestão documental (Santos, Serôdio e Ferreira 2017, 56, 67, 77). Das funcionalidades relacionadas com as coleções do museu, apenas dois em cada dez museus disponibiliza online o catálogo da sua coleção (Santos, Serôdio e Ferreira 2017, 44-45). Em termos de acessibilidade, salienta-se que $31 \%$ dos museus referiu ter aberto ao público as suas reservas/depósitos.

54 No seu Relatório Final, o Grupo de Projeto Museus no Futuro (Camacho 2021) divulgou um recente inquérito aplicado em fevereiro de 2020 pelo Observatório Português de Atividades Culturais às reservas de um conjunto de 33 unidades patrimoniais e 
museológicas (Museus, Palácios e Monumentos - MPM - dependentes daquele organismo e das Direções Regionais de Cultura), no qual concluiu que do total dos acervos das entidades inquiridas, correspondendo a mais de um milhão e $300 \mathrm{mil}$ objetos, encontra-se exposto cerca de $3 \% .^{9}$ O relatório identificou ainda que, devido à sobrelotação dos espaços e à carência de infraestruturas, em cerca de um terço dos MPM já não é possível acomodar novas incorporações (Camacho 2021, 79-80).

Da situação dos museus portugueses ressalta-se assim, no que diz respeito às políticas de incorporação, a par das deficiências observadas no diagnóstico, evidências de enormes dificuldades tanto na acomodação e preservação de coleções, como no acesso público a uma considerável percentagem dos bens culturais que as constituem.

\section{Instituições de memória e desenvolvimento sustentável}

Todo o setor cultural português, incluindo museus, bibliotecas e arquivos, debate-se há várias décadas, senão desde sempre, com parcos recursos humanos e materiais e mesmo o objetivo amplamente defendido em Portugal, de 1\% do Orçamento do Estado para a cultura, ainda não foi atingido.

Num mundo em alerta pandémico, o encerramento ou a restrição presencial dos serviços, a diminuição de visitantes nacionais e de turistas estrangeiros, o apelo do universo digital (ver UNESCO 2020; NEMO 2020), parecem trazer mudanças profundas na relação entre estes serviços culturais e os públicos. As políticas públicas de racionalidade de recursos, tarefa urgente e vital, irão obrigar a selecionar, gerir e agregar acervos de bens patrimoniais, em menos instituições e de forma integrada.

Para além dos efeitos da pandemia, as carências estruturais de recursos materiais e humanos, não obstante uma proclamada consciência da importância do papel agregador da cultura no viver da humanidade, situam estes vários processos e as nossas práticas profissionais num frágil equilíbrio.

Sendo múltiplos os desafios de gestão e de acesso público aos acervos de memória, a existência de legislação e instrumentos de trabalho específicos para cada uma das áreas significa que ainda não se formulou uma visão transversal, para que, não obstante objetos diferentes irem para sítios diferentes, possa haver uma gestão integrada das coleções e dos documentos.

Acresce ainda que no atual contexto mundial forçado pela presente pandemia, importa pensar holisticamente o valor dos acervos patrimoniais na valorização e na sustentabilidade das sociedades, num quadro de consciente seleção e uso de recursos. Esta nova ordem de sociabilidade pós-pandémica também reforçou a consciência de todos, da necessidade de cultura no quotidiano das pessoas, pois tornou mais suportável o isolamento social ou físico.

61 Os museus, arquivos e bibliotecas devem aproveitar e apostar nas vantagens que o ambiente digital e as redes sociais têm para divulgação de conteúdos, alinhando-se com os Objetivos do Desenvolvimento Sustentável da Agenda 2030 das Nações Unidas.

Em setembro de 2015, a Organização das Nações Unidas realizou uma cimeira na qual foi redigida e aprovada a Agenda 2030 (ONU 2015). Este documento é fundamental para todos os países e apresenta os Objetivos de Desenvolvimento Sustentável (ODS) para 
serem alcançados durante esta década (UNRIC 2016). Os 17 ODS e as 139 metas têm uma ambição universal e dizem respeito às áreas económicas, social, cultural e ambiental. Todos os objetivos são integrados e indivisíveis e necessitam de parcerias locais a globais. Assim, os estados, o setor privado e o público, as instituições, os cidadãos em geral são convidados a participar ativamente a melhorar o mundo, a promover a prosperidade, a proteger o ambiente. Os países foram convidados a construírem políticas, medidas e ações para o cumprimento dos objetivos (ONU 2019).

o desenvolvimento sustentável é a palavra-chave que unifica todos estes objetivos, conectando quatro dimensões: o ambiente, a sociedade, a economia e a cultura. No passado, a União Europeia demonstrara preocupação por este propósito, tendo apresentado, no artigo 3.․ do Tratado da União Europeia, um apelo para a urgência de uma política comum de coesão económica e social, no domínio ambiental, da agricultura, das pescas e da saúde, apelando ao desenvolvimento em geral dos estadosmembros (União Europeia 1992). Atualmente na União Europeia, o Eurostat apresenta regularmente relatórios sobre a sustentabilidade e a monitorização do cumprimento dos ODS (European Union 2019).

Em paralelo, é possível refletir sobre a sustentabilidade do património material e imaterial. O plano cultural é geralmente muito citado como um dos pilares da sustentabilidade: a Agenda 2030 apresenta o plano económico, social e ambiental também como contribuintes e como pilares interrelacionados com a cultura. As organizações GLAM (acrónimo de Galleries, Libraries, Archives and Museums) que trabalham e defendem o património cultural reconhecem que este envolve valores sociais, contributos da comunidade que relevam da democracia, da justiça social e das práticas tecnológicas mais próximas e mais sociais. A cultura e o património referem-se a todas as esferas da vida e a sua compreensão ultrapassa o trabalho das instituições associadas ao património. Há uma aceitação do modelo de uma cultura aberta em que cada cidadão pode ter um papel primordial e complementar às organizações GLAM (Wiktor-Mach 2019). Este cidadão é um ator vital que contribui e colabora para a coesão social e para uma forte sustentabilidade do património.

Com as recomendações dos 17 ODS (UNRIC 2016) - sobretudo nos objetivos "11 Cidades e comunidades sustentáveis", "16 - Paz, justiça e instituições eficazes" e "17 Parcerias para a implementação dos objetivos" - as parcerias globais fortalecem e revitalizam as instituições culturais GLAM com uma aproximação do património, que já não é algo apenas do passado, com outros interesses e perspetivas sociais e económicas, onde todas as culturas podem contribuir para o desenvolvimento sustentável. Alguns dos ODS tentam provar a relevância do património para o desenvolvimento, enquanto fonte de identidade coletiva, defendendo a cooperação com outros parceiros envolvidos na área da cultura, ou seja, que neste processo sejam incluídos os parceiros institucionais e o cidadão comum que possui informação e capacidade transformadora (Wiktor-Mach 2019).

66 Assumindo que os pilares da sustentabilidade são do domínio ambiental, económico, social, cultural e de governação participativa ${ }^{10}$, o ponto fulcral é como fazer e usar património enquanto recurso de desenvolvimento.

67 A necessidade da definição de políticas integradas, sob a visão de sustentabilidade dos territórios e das sociedades, dos quais fazem parte as instituições de memória, reforça a importância das coleções, no espaço e no tempo, e confere a responsabilidade a cada entidade de definir as suas estratégias de valorização e usufruto público do património 
à sua guarda, assumindo que desenvolver a sua coleção não é sinónimo de a aumentar (Mairesse 2010, 65).

68 A crise causada pela pandemia faz ressaltar a necessidade e a importância de políticas públicas para o setor, assim como de definição de estratégias e de aprofundamento e integração de modelos de gestão e de informação pela salvaguarda de património, priorizando o seu enraizamento territorial e social. o reconhecimento e a ativação de "comunidades patrimoniais" deverão fazer parte de tais estratégias, nomeadamente indo ao encontro dos objetivos da Convenção de Faro (Conselho da Europa 2005). ${ }^{11}$

Pode o digital representar uma oportunidade para que os objetos esquecidos encontrem visibilidade online? A necessidade de aumentar a quantidade de conteúdos a partilhar online pode ajudar a resgatar do esquecimento e do pó coleções em depósito ou em reserva? Ou, pelo contrário, vai significar um menor investimento e um menor interesse na fisicalidade das coleções, e aqui entram as opções pela desincorporação, alienação, venda e abate? A política de incorporação de objetos em museus e as aquisições feitas por museus públicos estão definidas na legislação, mas são insuficientes quer a análise e o trabalho de diagnóstico, quer a formulação e publicitação de políticas de incorporação e desincorporação.

É no contexto de projetos colaborativos entre instituições de memória e de estratégias participativas na salvaguarda de património que os profissionais surgem crescentemente como facilitadores e mediadores, realçando-se o seu potencial papel de agenciadores de interação social e de mudança (Filipe e Camacho 2018).

\section{Conclusão}

71 Com o objetivo proposto de analisar as políticas de incorporação e desincorporação transversalmente a museus, bibliotecas e arquivos (enquanto instituições de memória e de salvaguarda de património), as autoras fizeram um exercício experimental de reflexão sobre as linhas programáticas e de valorização dos acervos de memória, sob uma perspetiva comparativa, holística e integrada.

O presente artigo procura ser um contributo sobre a temática enunciada, a partir de uma breve contextualização geral, com a compilação de dados de caracterização institucional e enquadramento no plano legal, no panorama português. As limitações do nosso trabalho devem-se, por um lado, à quase inexistência de bibliografia sobre o assunto, e, por outro, à escassez de diagnósticos e de dados estatísticos que permitissem fazer uma análise transversal ao setor das instituições de memória. Note-se que as atuais Estatísticas da Cultura elucidam sobre bastantes aspetos do funcionamento dos museus, mas fornecem escassíssimos dados sobre bibliotecas e arquivos.

Cremos, no entanto, ter conseguido contrapor as diferentes realidades e as situações diferenciadas no que diz respeito a políticas de coleções em museus, bibliotecas e arquivos, em particular, relativamente à incorporação e desincorporação. Concluímos que a desincorporação, processo inverso à incorporação, necessário a uma política sustentada de coleções, é praticamente um não assunto, tanto no plano estratégico e programático das instituições, como ao nível da produção académica e científica. Consideramos, porém, que a legislação não é em si mesma limitativa de ação política, mas esta requer múltiplas definições estratégicas, assim como a consolidação e o reforço de meios, sob uma visão holística para o setor em análise. 

que ações como avaliação, eliminação e abate são desejáveis, embora nem sempre praticadas. A ênfase coloca-se sempre em "guardar", ainda que os depósitos se encontrem repletos e as instituições se debatam com a crónica ausência de espaço físico.

erifica-se que, nos museus, que se defrontam igualmente com uma persistente escassez de recursos físicos e humanos, a acumulação de bens culturais é desproporcional ao seu uso e acesso público, com um evidente problema de sobrelotação ou mesmo inexistência de espaços adequados de reservas museológicas, complementares aos espaços expositivos, onde supostamente se apresentem os objetos mais relevantes para a comunicação com os públicos.

Atenta ao impacto da pandemia, a nossa abordagem propôs-se assim enfatizar o papel social das instituições de memória e a importância, qualitativa e quantitativa, dos acervos patrimoniais, como um recurso potencial para o desenvolvimento sustentado. Será que em pós-pandemia as políticas públicas e o investimento no setor cultural, público e privado, apostando mais na transição digital e noutras formas inovadoras e participativas de usufruto, comunicação e divulgação do património, vão ser capazes de mobilizar a sociedade, para repensar o valor e a visibilidade dos acervos de memória? Será esta uma oportunidade de inovação e investimento na tecnologia, nas infraestruturas e na formação dos profissionais, a fim de preparar as instituições, em conjunto com as suas comunidades e territórios de referência, reconhecendo-as relevantes para o bem-estar individual e coletivo e para um desenvolvimento sustentável, em linha com os ODS e a Agenda 2030?

\section{BIBLIOGRAFIA}

Camacho, Clara Frayão, coord. 2021. Grupo de Projeto Museus no Futuro: Relatório Final. Lisboa: Direção-Geral do Património Cultural. http://patrimoniocultural.gov.pt/static/data/docs/ 2021/02/15/RelatorioMuseusnoFuturo.pdf

Carr, David. 2000. "In the Contexts of the Possible: Libraries and Museums as Incendiary Cultural Institutions.” RBM: A Journal of Rare Books, Manuscripts, and Cultural Heritage 1 (2): 117-134.

Conselho da Europa. 2005. Convenção-Quadro do Conselho da Europa Relativa ao Valor do Património Cultural para a Sociedade. Resolução da Assembleia da República n. ${ }^{4}$ 47/2008 de 12 de setembro, Diário da República, 1. série, n.ำ 177: 6640-6652. http://patrimoniocultural.gov.pt/media/ uploads/cc/ConvencaodeFaro.pdf

Constituição da República Portuguesa: VII Revisão Constitucional [2005]. https:// www.parlamento.pt/Legislacao/Paginas/ConstituicaoRepublicaPortuguesa.aspx

Decreto-Lei n.o 111/87 de 11 de março. Diário da República. 1aㅗ série-A, n.ํ58 (1987): 999.

Decreto-Lei n.ำ 16/93 de 23 de janeiro. Diário da República. 1ª́rérie-A, n.ำ 19 (1993): 264-270.

Decreto-Lei n. ${ }^{\circ}$ 447/88 de 10 de dezembro. Diário da República. 1ª série-A, n.ำ 284 (1988): 4885.

MIDAS, 13 | 2021 
Decreto-Lei n.․ 47/2004 de 3 de março. Diário da República. 1ª série-A, n.ํ 53 (2004): 1161-1162.

Decreto-Lei n.ํำ 71/87 de 11 de fevereiro. Diário da República. 1ª série-A, n.ํㅜ 35 (1987): 528-534.

European Union. 2019. Sustainable Development in the European Union: Monitoring Report on Progress Towards the SDGs in an EU Context. Luxembourg: Publications Office of the European Union. https://ec.europa.eu/eurostat/documents/3217494/9940483/KS-02-19-\%20165-EN-N.pdf/ 1965d8f5-4532-49f9-98ca-5334b0652820

Filipe, Graça, e Clara Frayão Camacho. 2018. "Que Futuro Queremos dar ao(s) Museu(s)? Algumas Questões da Museologia Contemporânea, entre o Panorama Mundial e a Situação em Portugal." Revista Património 5: 49-59.

Gob, André, e Noémie Drouguet. 2006. La Muséologie. Histoire, Développement, Enjeux Actuels. Paris: Armand Colin.

Greene, Mark A. 2002. "What Were We Thinking? A Call to Embrace Reappraisal and Deaccessioning." Provenance, Journal of the Society of Georgia Archivists 20 (1): 33-49.

Greene, Mark. 2015a. “Acquisition Policy.” In Encyclopedia of Archival Science, editado por Luciana Duranti e Patricia. C. Franks, 9-12. Lanham: Rowmand \& Litlefield.

Greene, Mark. 2015b. “Collection-Management Policy.” In Encyclopedia of Archival Science, editado por Luciana Duranti e Patricia. C. Franks, 142-145. Lanham, Maryland: Rowmand \& Litlefield.

Hjerppe, Roland. 1994. “A Framework for the Description of Generalised Documents.” In Knowledge Organization and Quality Management: Proceedings of the Third International ISKO Conference 20-24 June 1994 Copenhagen, Denmark, vol. 4, Advances in Knowledge Organization, editado por Hanne Albrechtsen e Susanne Oernager, 173-180. Frankfurt: Indeks Verlag.

ICOM. 2017. Statutes: As Amended and Adopted by the Extraordinary General Assembly on 9th June 2017 (Paris, France). ICOM (International Council of Museums). https://icom.museum/wp-content/ uploads/2018/07/2017_ICOM_Statutes_EN.pdf

ICOM. 2019. Guidelines on Deaccessioning of the International Council of Museums. ICOM (International Council of Museums). https://icom.museum/wp-content/uploads/2019/10/Guidelines-onDeaccessioning-of-the-International-Council-of-Museums.pdf

INE. 2019. Estatísticas da Cultura - 2018. Lisboa: Instituto Nacional de Estatística (INE).

Jackson, Laura. 2015. “Deaccessioning." In Encyclopedia of Archival Science, editado por Luciana Duranti e Patricia. C. Franks, 155-157. Lanham, Maryland: Rowmand \& Litlefield.

Kaczmarek, Joanne. 2007. “The Complexities of Digital Resources: Collection Boundaries and Management Responsibilities.” Journal of Archival Organization 4 (1-2): 215-227.

Ladkin, Nicola. 2004. “Collections Management.” In Running a Museum: A Practical Handbook, editado por Patrick J. Boylan, 17-30. Paris: ICOM.

Lei n.ำ 107/2001 de 8 de setembro. Diário da República. 1ª́ série-A, n.ำ 209 (2001): 5808-5829.

Lei n.ำ 47/2004 de 19 de agosto. Diário da República. 1ª série-A, n.ำ 195 (2004): 5379-5394.

Lord, Barry, Gail Dexter Lord, e Lindsay Martin, eds. 2012. Manual of Museum Planning: Sustainable Space, Facilities, and Operations. Lanham: Altamira Press.

Lord, Gail Dexter, e Barry Lord. (1997) 2009. The Manual of Museum Management. New York: Altamira Press. 
Luna, Maria Isabel Soares. 2011. “Incorporação e Desincorporação em Museus. História, Realidade e Perspectivas Futuras.” Dissertação de mestrado em Estudos Museológicos, ISCTE - Instituto Universitário de Lisboa.

Mairesse, François. 2010. “Collection Strategies Now!” In Encouraging Collections Mobility - A Way Forward for Museums in Europe, editado por Susanna Pettersson, Monika Hagedorn-Saupe, Teijamari Jyrkkiö e Astrid Weij, 54-71. Helsinki: Finnish National Gallery.

Matassa, Freda. 2010. “Active collections: Re-Visiting our Collection for More and Better use." In Encouraging Collections Mobility - A Way Forward for Museums in Europe, editado por Susanna Pettersson, Monika Hagedorn-Saupe, Teijamari Jyrkkiö e Astrid Weij, 107-135. Helsinki: Finnish National Gallery.

Matassa, Freda. 2011. Museum Collections Management: A Handbook. London: Facet Publishing.

Melo, Daniel. 2004. A Leitura Pública no Portugal Contemporâneo (1926-1987). Lisboa: Imprensa das Ciências Sociais.

Mensch, Léontine Meijer-van, e Peter van Mensch. 2010. "From Disciplinary Control to CoCreation - Collecting and the Development of Museums as Praxis in the Nineteenth and Twentieth Century." In Encouraging Collections Mobility - A Way Forward for Museums in Europe, editado por Susanna Pettersson, Monika Hagedorn-Saupe, Teijamari Jyrkkiö e Astrid Weij, 33-53. Helsinki: Finnish National Gallery.

Mensch, Peter van, e Léontine Meijer-van Mensch. 2011. New Trends in Museology. Celje: Museum of Recent History Celje.

NEMO. 2020. Survey on the Impact of the COVID-19 Situation on Museums in Europe: Final Findings and Recommendations. NEMO (Network of European Museum Organisations). https://www.ne-mo.org/ fileadmin/Dateien/public/NEMO_documents/

Final_Findings_and_Recommendations_CVOID19_12.05.2020.pdf

Nunes, Manuela Barreto. 2018. Bibliotecas Escolares: Gestão, Desenvolvimento e Curadoria de Coleções na Era Digital. Lisboa: Rede de Bibliotecas Escolares - Ministério da Educação.

ONU. 2015. Agenda 2030: Objetivos para o Desenvolvimento Sustentável. Organização das Nações Unidas (ONU). https://unric.org/pt/objetivos-de-desenvolvimento-sustentavel/

ONU. 2015. Transforming Our World: The 2030 Agenda for Sustainable Development. Organização das Nações Unidas (ONU). https://sustainabledevelopment.un.org/post2015/transformingourworld/ publication

ONU. 2019. The Sustainable Development Goals Report. Organização das Nações Unidas (ONU). https://unstats.un.org/sdgs/report/2019/The-Sustainable-Development-Goals-Report-2019.pdf Resolução da Assembleia da República n.ำ 47/2008. Diário da República. 1. a série, n. 177 (2008): 6640-6652.

Ribeiro, Fernanda. 2005. "Gestão da Informação/Preservação da Memória na Era Pós-Custodial: Um Equilíbrio Precário?" In Conservar para quê? 8. ${ }^{a}$ Mesa-Redonda de Primavera, coordenado por Vítor Oliveira Jorge, 77-84. Porto; Coimbra: Faculdade de Letras da Universidade do Porto, Departamento de Ciências e Técnicas do Património; Centro de Estudos Arqueológicos das Universidades de Coimbra e Porto.

Santos, Jorge, Conceição Serôdio, e Fernanda Ferreira. 2017. Diagnóstico aos Sistemas de Informação nos Museus Portugueses: Relatório final. Lisboa: Grupo de Trabalho Sistemas de Informação em Museus (GT-SIM) da Associação Portuguesa de Bibliotecários, Arquivistas e Documentalistas 
(BAD). https://noticia.bad.pt/wp-content/uploads/2017/06/

GTSIM_DSIM_Relat\%c3\%b3rioFinal.pdf

Santos, Luís Filipe Reis. 2011. “Gestão de Colecções nas Bibliotecas Públicas Portuguesas: Da Teoria à Prática. Sugestões para um Guia de Procedimentos.” Dissertação de mestrado em Ciências Documentais, Universidade da Beira Interior.

Serôdio, Conceição. 2018. "Contributos para uma Gestão Integrada dos Acervos nos Museus Portugueses." MIDAS 9.

Silva, Ana Margarida Dias, e Leonor Calvão Borges. 2020. "How Bits and Bytes Widen Cultural Heritage Boundaries." Journal of Digital Media \& Interaction 3 (7): 10- 19.

Silva, Ana Margarida Dias, Leonor Calvão Borges, e Cristiana Freitas. 2019. “A Práxis da Classificação nos Arquivos Municipais Portugueses." 13ํㅡㄹ Encontro Nacional de Arquivos Municipais https://publicacoes.bad.pt/revistas/index.php/arquivosmunicipais/article/view/1976

Silva, Armando Malheiro da, e Fernanda Ribeiro. 2002. Das 'Ciências' Documentais à Ciência da Informação: Ensaio Epistemológico para um Novo Modelo Curricular. Porto: Afrontamento.

Timms, Katherine. 2009. "New Partnerships for Old Sibling Rivals: The Development of Integrated Access Systems for the Holdings of Archives, Libraries, and Museums." Archivaria 68 (1): 67-95.

UNESCO. 2020. Museums Around the World in the Face of COVID-19. Paris: UNESCO (United Nations

Educational, Scientific and Cultural Organization). https://unesdoc.unesco.org/ark:/48223/ pf0000373530

União Europeia. Tratado da União Europeia (92/C 191/01). Jornal Oficial das Comunidades Europeias n. 191 (1992): 1-112. https://eur-lex.europa.eu/legal-content/PT/TXT/PDF/?uri=CELEX:11992M/ TXT\&from=EN

UNRIC. 2016. Guia sobre Desenvolvimento Sustentável: 17 Objetivos para Transformar o Nosso Mundo. [Bruxelas]: Centro de Informação Regional das Nações Unidas para a Europa Ocidental. https:// www.instituto-camoes.pt/images/ods_2edicao_web_pages.pdf

Vieira, João. 1990. Orientações Gerais para a Gestão de Documentos de Arquivo. Lisboa: IPA - Instituto Português de Arquivos.

Wijsmuller, Dieuwertje. 2017. Deaccessioning \& Disposal in Europe 2008-2017. A Research on Possibilities and Attitudes Across the European Member States. https://www.museumsanddeaccessioning.com/ wp-content/uploads/Deaccessioning-disposal-Europe-2008-2017-D.-Wijsmuller.pdf

Wiktor-Mach, Dobrosława. 2019. “Cultural Heritage and Development: UNESCO’s New Paradigm in a Changing Geopolitical Context.” Third World Quarterly 40 (9): 1593-1612.

\section{NOTAS}

1. Na literatura científica e académica das últimas três décadas aparecem sob a designação comum de: "instituições de memória", "instituições culturais", "cultural heritage agencies/ institutions", "LAM" (acrónimo de Libraries, Archives and Museums, ou "GLAM" se se juntarem as galerias), ou "cultural repositories" (Silva e Borges 2020). Carr (2000) e Hjerppe (1994), por exemplo, também incluem no lote das instituições ligadas à memória e ao património: monumentos e sítios, sociedades históricas, jardins botânicos, jardins zoológicos e parques, entre outros.

2. De acordo com o ICOM: «a museum is a non-profit, permanent institution in the service of society and its development, open to the public, which acquires, conserves, researches, 
communicates and exhibits the tangible and intangible heritage of humanity and its environment for the purposes of education, study and enjoyment» (ICOM 2017, 3).

3. Em Deaccessioning and Disposal in Europe 2008-2017, Dieuwertje Wijsmuller (2017) identificou duas tendências em relação à desincorporação em museus: uma de países mais de tradição anglosaxónica, e outra de países mais de tradição latina, em que se inclui Portugal.

4. No seu trabalho, Luna (2011) estabeleceu como universo a indagar o conjunto dos documentos normativos de museus portugueses que, na semana de 4 a 10 de julho de 2011, estavam disponíveis e acessíveis em linha, através da internet, procedendo à recolha e análise de um total de 52 documentos produzidos entre 2000 e 2010, representando 37 instituições museológicas distribuídas por 32 entidades tutelares. A amostra de trabalho desta museóloga foi constituída pelos 25 documentos que faziam referência direta à desincorporação museal: 15 políticas de incorporações (60\%), 9 regulamentos internos (36\%) e um programa museológico (4\%).

5. As entidades consideradas cumprem os cinco critérios de apuramento adotados: 1) museus que têm pelo menos uma sala de exposição; 2) museus abertos ao público (permanente ou sazonal); 3) museus que têm pelo menos um conservador ou técnico superior (incluindo pessoal dirigente); 4) museus que têm orçamento (ótica mínima: conhecimento do total da despesa); e 5) museus que têm inventário (ótica mínima: inventário sumário). Refira-se que os 431 museus correspondem a 63,4\% dos museus em atividade em Portugal, dado que um número significativo de museus não cumpre em simultâneo o conjunto dos cinco critérios definidos (INE 2019, 90).

6. Distribuição do número de bens, num total de 19839225 segundo o tipo: Arqueológicos 3851 830; Artísticos e históricos 2078 180; Bibliográficos e arquivísticos 6825 124; Técnico-científicos e industriais 618 934; Etnográficos 369 219; Naturais vivos 26 747; Naturais não vivos 2458 926; Outros 3610265 (INE 2019, 109).

7. Em Portugal, desde 1973, a APBAD tem procurado juntar esforços dos profissionais da informação e documentação na defesa do setor junto da sociedade portuguesa. E desde 2012 o GTSIM tem trabalhado e contribuído para uma visão integrada das coleções e da documentação dos museus, tendo por foco as relações informacionais (Serôdio 2018).

8. A equipa responsável pelo estudo foi composta por Jorge Santos (coordenação), Conceição Serôdio, Fernanda Ferreira, Maria Manuel Velasquez; Margarida Dias da Silva e Patrícia Costa. A apresentação do estudo foi realizada em abril de 2017 no ISCTE-IUL e o relatório disponibilizado em formato digital (ver Santos, Serôdio e Ferreira 2017).

9. O citado relatório tem «em consideração que as estimativas dos organismos de referência internacional apontam para que cerca de $90 \%$ dos objetos dos museus à escala mundial se encontram em reservas» (Camacho 2021, 79).

10. A Recomendação do Comité de Ministros dos estados-membros sobre a estratégia para o património cultural europeu para o século XXI (adotado pelo Comité de Ministros a 22 de fevereiro de 2017) refere a promoção da governação participativa, a par da componente social, do desenvolvimento territorial e económico e da componente do conhecimento e da educação (p. 9) e inclui nas suas recomendações (p. 13) a promoção e a avaliação das práticas e procedimentos de participação cidadã. http://anoeuropeu.patrimoniocultural.gov.pt/wp-content/uploads/ 2017/08/Estratégia-para-o-Património-Cultural-para-o-século-XXI-.pdf (consultado em novembro 26, 2021).

11. Aprovada em Portugal em 2008, esta Convenção define "comunidade patrimonial" como uma comunidade «composta por pessoas que valorizam determinados aspetos do património cultural que desejam, através da iniciativa pública, manter e transmitir às gerações futuras» (Conselho da Europa 2005, artigo 2, b, tradução das autoras). 


\section{RESUMOS}

Este artigo, suscitado pela partilha de conhecimentos e de experiências profissionais, pretende contribuir para uma reflexão em torno das políticas de incorporação e desincorporação das instituições de memória (arquivos, bibliotecas e museus), num contexto em que estas se procuram adaptar a problemas estruturais agravados pela pandemia covid-19. Como a gestão da memória coloca a todas as instituições que a promovem o problema da sua relação com o esquecimento, componentes indissociáveis em todas as sociedades e culturas, e reconhecendo que nem todos os processos de incorporação de bens culturais são irreversíveis, a nossa reflexão abarca esta problemática e pretende salientar a necessidade de políticas sustentáveis de desenvolvimento das coleções. Com base na legislação e tendo por referência bibliografia científica e académica e estudos sobre a matéria, procura-se problematizar: a questão da gestão das coleções e arquivos em cada uma das instituições de memória; as diferenças e as similaridades existentes entre cada uma elas; e o posicionamento de cada uma face à comunicação em ambiente digital. Conclui-se que a desincorporação, processo inverso à incorporação, pode ser um procedimento necessário e que os dois são complementares, num plano estratégico e programático das instituições. Mas a questão está longe de gerar consensos e tem-se demonstrado que requer profunda reflexão e debate científico, tanto no campo profissional, tendencialmente mais sujeito ao confronto direto com situações de crise, como no âmbito académico, porventura com maior margem crítica e prospetiva.

This article, prompted by the sharing of knowledge and experiences of the authors, aims to contribute to a reflection on issues surrounding the policies of incorporation and disincorporation of memory institutions (archives, libraries and museums), especially in a context in which their functioning seeks to adapt to structural problems aggravated by the covid-19 pandemic. As the management of memory poses to all the institutions that promote it the problem of its relationship with forgetfulness, inseparable components in all societies and cultures, and recognizing that not all processes of incorporation of cultural goods are irreversible, our reflection encompasses this issue and intends to highlight the need for sustainable collection development policies. Based on legislation and with reference to scientific and academic bibliography and studies on the subject, the authors seek to problematize: the issue of managing collections and archives in each one of the memory institutions; the differences and similarities between them; and the positioning of each one in relation to communication in a digital environment. It is concluded that deaccessioning, an inverse process to accessioning, may be a necessary procedure and that the two are complementary, in a strategic and programmatic plan of the institutions. But the issue is far from generating consensus and it has been shown that it requires deep reflection and scientific debate, both in the professional field, which tends to be more subject to direct confrontation with crisis situations, and in the academic sphere, perhaps with greater critical and prospective margins.

\section{ÍNDICE}

Palavras-chave: políticas culturais e museus, gestão de coleções, sustentabilidade, política de incorporações, desincorporação

Keywords: cultural policies and museums, collections management, sustainability, collecting policy, deaccessioning 


\section{AUTORES}

\section{GRAÇA FILIPE}

É museóloga, investigadora integrada do História, Territórios e Comunidades - CFE NOVA FCSH, docente do mestrado em Museologia da Faculdade de Ciências Sociais e Humanas (FCSH) da Universidade Nova de Lisboa e técnica superior da Câmara Municipal do Seixal (Ecomuseu Municipal). Licenciada em História (1980, Faculdade de Letras - Universidade de Lisboa), mestre em Museologia e Património (2001, FCSH - Universidade Nova de Lisboa) e pós-graduada em Museologia Social (1991, Universidade Autónoma de Lisboa), tem por domínios de investigação a museologia, os estudos de património e a história contemporânea.

História, Território e Comunidades - CFE NOVA FCSH, Av. de Berna 26 C, 1069-061 Lisboa, Portugal, gracafilipe@mail.telepac.pt

\section{CONCEIÇÃO SERÔDIO}

Licenciada em Filosofia pela Faculdade de Letras da Universidade de Lisboa. Pós-graduada em Ciências Documentais pela Universidade Autónoma de Lisboa e em Gestão e Empreendedorismo Cultural e Criativo pelo ISCTE - Instituto Universitário de Lisboa. Áreas de investigação: gestão integrada de informação em museus e património industrial. Fundadora do Grupo de Trabalho Sistemas de Informação em Museus (GT-SIM), da Associação Portuguesa de Bibliotecários, Arquivistas e Profissionais de Informação e Documentação. Desenvolve atividade profissional no Museu de Cerâmica de Sacavém, onde integra a equipa de gestão de acervos, investigação, produção de exposições e edições no âmbito do património industrial de Loures. Câmara Municipal de Loures, Museu de Cerâmica de Sacavém, Rua Álvaro Pedro Gomes, Urbanização Real Forte, 2685-145 Sacavém, Loures, Portugal, conceicaoserodio@gmail.com

\section{LEONOR CALVÃO BORGES}

É arquivista, investigadora do CITCEM - Centro de Investigação Transdisciplinar «Cultura, Espaço e Memória» da Universidade do Porto e assessora parlamentar na Divisão de Informação Legislativa e Parlamentar da Assembleia da República. Licenciada em Filosofia (1985) pela Universidade Nova de Lisboa, pós-graduada em Ciências Documentais - opção Arquivo (1989) e mestre em Paleografia e Diplomática pela Faculdade de Letras da Universidade de Lisboa. Doutoranda em Ciência da Informação na Universidade de Coimbra.

Divisão de Informação Legislativa e Parlamentar da Assembleia da República, Avenida D. Carlos I, 130 - 3, 1200-651 Lisboa, Portugal, leonorcborges@gmail.com

\section{ANA MARGARIDA DIAS DA SILVA}

É aluna do doutoramento em Ciência da Informação da Faculdade de Letras da Universidade de Coimbra, mestre em Ciência da Informação e Documentação pela Faculdade de Ciências Sociais e Humanas da Universidade Nova de Lisboa, e mestre em História Contemporânea pela Faculdade de Letras da Universidade de Coimbra. Tem dedicado a sua investigação a temas relacionados com organização e representação da informação, arquivos pessoais e familiares, arquivos 2.0, arquivos colaborativos, instituições de memória e participação cidadã. Desde 2019 é técnica superior no Departamento de Ciências da Vida da Universidade de Coimbra. É investigadora do CIC.Digital - Centro de Investigação em Comunicação, Informação e Cultura Digital e do CITCEM Centro de Investigação Transdisciplinar «Cultura, Espaço e Memória» da Universidade do Porto. Colégio de S. Bento, Calçada Martim de Freitas, 3000-456 Coimbra, Portugal, anasilva@fl.uc.pt 